\title{
Mixing of stratified flow around bridge piers in steady current
}

\author{
Jensen, Bjarne; Carstensen, Stefan; Christensen, Erik Damgaard
}

Published in:

Journal of Hydraulic Engineering

Link to article, DOI:

10.1061/(ASCE)HY.1943-7900.0001481

Publication date:

2018

Document Version

Peer reviewed version

Link back to DTU Orbit

Citation (APA):

Jensen, B., Carstensen, S., \& Christensen, E. D. (2018). Mixing of stratified flow around bridge piers in steady current. Journal of Hydraulic Engineering, 144(8), [04018041]. https://doi.org/10.1061/(ASCE)HY.19437900.0001481

\section{General rights}

Copyright and moral rights for the publications made accessible in the public portal are retained by the authors and/or other copyright owners and it is a condition of accessing publications that users recognise and abide by the legal requirements associated with these rights.

- Users may download and print one copy of any publication from the public portal for the purpose of private study or research.

- You may not further distribute the material or use it for any profit-making activity or commercial gain

- You may freely distribute the URL identifying the publication in the public portal

If you believe that this document breaches copyright please contact us providing details, and we will remove access to the work immediately and investigate your claim. 
HY10745

\title{
Mixing of Stratified Flow around Bridge Piers in Steady Current
}

\author{
Bjarne Jensen $^{1}$, Stefan Carstensen ${ }^{2}$ and Erik Damgaard Christensen ${ }^{3}$
}

\begin{abstract}
This paper presents the results of an experimental and numerical investigation of the mixing of stratified flow around bridge pier structures. In this study, which was carried out in connection with the Fehmarnbelt Fixed Link environmental impact assessment, the mixing processes of two-layer stratification was studied where the lower level had a higher salinity than the upper layer. The physical experiments investigated two different pier designs. A general study was made regarding forces on the piers where also the effect of the current angle relative to the structure was included. This was done in uniform flow with no stratification. Following this, a study was performed where the mixing efficiency was investigated in the case of a stratified flow. The numerical investigations supplemented the findings of the physical experiments and gave information on scale effects, drag coefficients for low velocities and natural background mixing. The present study provided a general understanding and knowledge about the mixing processes around bridge piers as well as a direct measure of the impact of the proposed designs

1 Senior Hydraulic Engineer, DHI, Ports \& Offshore Technology Department, Agern Alle’ 5, DK-2970 Hørsholm, Denmark. E-mail: bjj@dhigroup.com

2 Associate Professor, Fluid Mechanics, Coastal and Maritime Engineering Section, Department of Mechanical Engineering, Technical University of Denmark, Nils Koppels Alle’ 403, DK-2800 Kgs. Lyngby, Denmark. E-mail: scar@mek.dtu.dk

3 (corresponding author) Professor, Head of Fluid Mechanics, Coastal and Maritime Engineering Section, Department of Mechanical Engineering, Technical University of Denmark, Nils Koppels Alle' 403, DK-2800 Kgs. Lyngby, Denmark. E-mail: edch@mek.dtu.dk
\end{abstract}


on the natural stratification.

Keywords: Stratified flow, Mixing, Marine structures, Model scale experiments, NavierStokes equations, Turbulence modelling

\section{Introduction}

In coastal and marine engineering related to infrastructure projects, it is a common task to design and construct crossings of rivers, fjords, estuarine waters etc. This involves the construction of bridge piers to be placed in the water environment thus giving an impact on the natural undisturbed environment. In waters where a natural stratification of the water column occurs it is a concern whether the introduction of bridge piers in the flow will cause a substantial mixing of the natural stratification and affect the ecosystem. An example of this phenomeinon was investigated in (Miller and Valle-Levinson 1996), where the influence of a bridge pier was analysed through field measurements in Lower Chesapeake Bay. This study investigates the effect of bridge piers in a stratified flow, as exemplified by the inner Danish waters, as part of the environmental assessment of the new Fehmarn Belt fixed link between Denmark and Germany. It aims at quantifying the effect in terms of the enhanced mixing, while the added resistance due to the presence of bridge piers was investigated in (Jakobsen et al. 2010). The Baltic Sea and the inner Danish Waters including the Great Belt, Øresund, and Fehmarn Belt are characterised by a surplus of freshwater discharge from the rivers at the Baltic Sea resulting in a brackish surface layer. This layer is separated from a dense bottom layer with a higher salinity by a halocline. An important process in relation to maintaining this environmental system is the ventilation of the dense bottom layer and the deep basins, such as the Arkona Basin and the Bornholm Basin. This is achieved by inflow events of salt water from the North Sea via the Danish straits. These inflow 
events takes place as both barotropic and baroclinic bottom flows several times every year. The processes of inflow to the Baltic Sea and entrainment to the Arkona Basin were investigated in e.g. (Fennel and Sturm 1992) and (Arneborg et al. 2007).

Several detailed studies exist on the physical processes of natural mixing of stratified flows, e.g., (Grubert 1989), (Fernando 1991), (Ivey and Imberger 1991), (Strang E. J. and Fernando 2001), and (Peltier and Caulfield 2003). Of interest for the present study and its objective is enhanced mixing, which implies that a higher mixing takes place than that of a natural flowing environment. The bridge piers introduce enhanced mixing in this case. This has not been investigated to the same extent although some previous works exist that are of relevance.

When a bridge pier is introduced into the flow the work performed by the pier (reaction force) on the ambient water introduces turbulent kinetic energy from the generated vortex shedding and smaller scale turbulence. In an uniform non-stratified flow the turbulent flow structures will undergo a turbulent cascade where smaller and smaller eddies are being formed and finally dissipated into heat. In the stratified case some of the energy will be used to mix the two layers, redistributing heavy bottom water into the lighter upper layer (e.g. (Rouse and Dodu 1955), (Holmboe 1962) and (Smyth and Winters 2003)) .

The work of (Pedersen 1986) gives a starting point for a general background on stratified flows and mixing. (Pedersen 1986) introduced the bulk flux Richardson number, $R_{f}^{T}$, as an alternative to the conventional flux Richardson number, $R_{f}$. The bulk flux Richardson number may be defined as the ratio between the gain in potential and turbulent kinetic energy due to the entrained mass, and the energy available for the turbulence. 


$$
R_{f}^{T}=\frac{\text { Energy gained }}{\text { Energy produced }}\left(=1-\frac{\text { Energy dissipated }}{\text { Energy produced }}\right)
$$

One of the hypothesis in (Pedersen 1986) is, that $R_{f}^{T}$ is nearly constant for natural unconfined surface flows. Based on an order of magnitude analysis the values of the bulk flux Richardson number was suggested to be $R_{f}^{T}=0.045$ for cusp-type mixing and $R_{f}^{T}=0.18$ for vortex type mixing. In (Jürgensen 1989) experiments were conducted to further investigate the mixing, in this case due to structures such as piers, dams, and ships. The bulk flux Richardson number was also applied here to quantify the mixing efficiency. In order to introduce a structural parameter into the variation of $R_{f}^{T}$, the measured mixing was related to a parameter $y / D$ where, for a bridge pier, $D$ was the pier diameter and $y$ was the depth of the upper layer of the two layer stratification. Experiments were conducted with a stratified steady current without the pier in the flume in order to determine the background mixing. This was found to be up to $R_{f}^{T} \approx 0.04$, which corresponds to the value suggested by (Pedersen 1986) for natural surface flows. However, the laboratory measurements should be compared to natural flows with caution due to the effects of the experimental procedure such as the side walls of the flume. (Jürgensen 1989) reported the mixing due to piers as values being corrected for the background mixing. $\mathrm{He}$ found that the mixing efficiency originating from the piers alone was in the range of $0.01<R_{f}^{T}<0.05$ however with some data values up to $R_{f}^{T} \approx 0.09$ for low values of $y / D$. The investigations prior to the Great Belt fixed link generated a number of studies with the focus on the enhanced mixing due to bridge piers. In (Møller and Ottesen Hansen 1997) experiments were conducted with bridge piers in a stratified steady current in a similar setup as applied in (Jürgensen 1989). The experiments were performed with the bridge piers being fixed 
in the experimental flume and a stratified current was generated. The experiments were repeated both with and without the bridge piers in order to separate the natural mixing at the interface from the additional mixing caused by the piers. These experiments showed that the mixing efficiency was close to zero and depending on the definitions could be either positive and negative. A negative value of $R_{f}^{T}$ corresponds to the stratification to be less mixed due to the piers, which does not give physical meaning.

Also field campaigns have been conducted in relation to mixing due to bridge piers. As part of the studies for the Fehmarn Belt fixed link a number of field experiments were performed at the Great Belt fixed link. In (Lass et al. 2008) a field campaign was reported where measurements were performed at the Great Belt bridge piers. They performed measurements both upstream and downstream the piers of the western part of the bridge with CTD (Conductivity, Temperature, and Depth). In this way the stratification was identified as well as the wake behind the piers and the associated vortex shedding. The results showed an enhanced mixing downstream the piers in the wake region when the internal Froude number was close to 1. For smaller Froude numbers no significant enhanced mixing was observed.

Previous work has shown a great variability in the mixing efficiency due to obstacles such as bridge piers. This work had the main objective to document the enhanced mixing due to the proposed Fehmarn Belt fixed link bridge piers. In addition to this it also provides information on the enhanced mixing which may add to the overall understanding of the topic for future use. The results can for instance be parameterised and used in oceanographic models that analyses the effect on a large scale, see (Rennau et al. 2012).

The results found in this study will be discussed related to earlier studies of which important references are given in the following. (Turner 1968) studied influence of molecular 
diffusivity on turbulent entrainment across a density interface. (Linden 1980) measured mixing produced by dropping a horizontal grid through a sharp density interface. A great number of experiments have been carried out where turbulence is generated by towing a bi-planar grid horizontally through an ambient stratified water column (see e.g. (Britter et al. 1983) and (Rehmann and Koseff 2004)). (Holford and Linden 1999) towed a rake of vertical bars (monoplaner grid) through an ambient stratified water column.

The scope of this work was to apply a combination of physical model experiments and detailed numerical modelling to quantify the effect of the bridge piers on the natural stratified water environment. The paper is organized as follows. Following the introduction a methods section is given regarding the physical processes, definition of mixing efficiency, and the investigated bridge pier geometries. Following this we describe the physical model experiments, and the numerical modelling set-up. Then the results are presented followed by a discussion section. In the discussion the results from both the physical experiments and the numerical modelling are treated. Finally the main conclusions are drawn in the last section.

\section{Methods}

\section{Mixing efficiency}

The term mixing efficiency is, in this study, related to the bulk flux Richardson number. In the present study the energy gained was the change in potential energy $\left(\Delta E_{p o t}\right)$ by the vertical redistribution of the density profile, as the water column reverts to an ambient state after each run in the physical experiments or downstream the pier in the numerical simulations. The energy produced was the turbulent kinetic energy (TKE) generated when the bridge pier was dragged through the ambient water column as was the case for the physical experiments, or exposed to the 
steady current in the numerical simulations. The bulk flux Richardson number can therefore be expressed as:

$$
R_{f}^{T}=\frac{\Delta E_{p o t}}{\mathrm{TKE}}
$$

The turbulent kinetic energy is approximately equal to the work performed when the bridge pier is dragged through the ambient water column or the steady current flows around the bridge pier. This work can be expressed as:

$$
W=\int_{0}^{t}-F_{x} U d t
$$

where $F_{x}$ is the measured in-line force on the bridge pier, $U$ is the mean velocity of the bridge pier for the physical experiments, or the depth averaged free stream velocity for the numerical simulations, and $t$ is the run-time for the experiment or the simulation. The mixing efficiency may therefore be written as:

$$
R_{f}^{T}=\frac{\Delta E_{p o t}}{W}
$$

The in-line force on the bridge pier may be written as:

$$
F_{x}=F_{D}+F_{I}=\frac{1}{2} \rho C_{D} A_{f} U|U|+\rho C_{m} \bar{A} h \frac{d U}{d t}
$$

where $F_{D}$ is the drag force, $F_{I}$ is the inertia force, $\rho$ is the density, $C_{D}$ is the drag coefficient, $A_{f}$ is the frontal projected area of the bridge pier, $C_{m}$ is the inertia coefficient, and $\bar{A}$ is the average horizontal cross sectional area. For a constant velocity $(d U / d t=0)$ the in-line force reduces to the drag force:

$$
F_{x}=F_{D}=\frac{1}{2} \rho C_{D} A_{f} U|U|
$$

The drag coefficients were hereby determined based on the measured or simulated mean 
drag force as:

$$
C_{D}=\frac{\bar{F}_{D}}{\frac{1}{2} \rho A_{f} \bar{U}^{2}}
$$

where $\bar{F}_{D}$ is the mean drag force and $\bar{U}$ is the mean current free stream velocity. The potential energy, $E_{p o t}$, was derived from the density profiles measured or simulated upstream and downstream the bridge piers as:

$$
E_{p o t}=A \int_{0}^{h} \rho g z d z
$$

Where $A$ is the horizontal reference area upstream and downstream the pier.

\section{Characteristics of bridge piers}

Two generic bridge piers were investigated. The geometries of the generic bridge piers were taken from a Fehmarnbelt feasibility study in 1998. An elliptic pile with a rectangular plinth at the top and an identical elliptical shape without a plinth on top. These are referred to as pier 1 and 2 as presented in Fig. 1.

Only one geometrically scaled model (1:49) was constructed for the physical model experiments. The model was a $531 \mathrm{~mm}$ high elliptic pile with a square plinth. The major and minor axis of the elliptic pile cross-section was $571 \mathrm{~mm}$ and $235 \mathrm{~mm}$, respectively. The cross-section of the square plinth was $132 \mathrm{~mm}$ by $285 \mathrm{~mm}$. The two elliptical models were achieved by varying the total water depth, respectively $\mathrm{h}=571 \mathrm{~mm}$ and $\mathrm{h}=500 \mathrm{~mm}$. Surface roughness was created by gluing sand grains on the model surface. The sand grains had a mean diameter of $\mathrm{d}_{50}=0.5 \mathrm{~mm}$. For the numerical modelling the surface roughness was described by a rough surface wall function where the roughness of $\mathrm{d}_{50}=2.45 \mathrm{~cm}$ in full-scale was applied, see section on simulations. The 
roughness height applied is in the upper end of the range of values recommomended by guidelines, but serve to limit the effect of the Reynolds number in the experiments.

\section{Experiments}

The experiments were carried out in the towing tank at the Technical University of Denmark (DTU). The measurement section of the tank was $35 \mathrm{~m}$ long, $3.0 \mathrm{~m}$ wide and $1.0 \mathrm{~m}$ high but the length of the measurement section was shortened by two bulkheads to $26.74 \mathrm{~m}$ for these experiments. Figure 2 shows a sketch of the measurement section of the towing tank. In the measurement section a two-layer stratified water column with different salinity was established as described below. The bulkheads completely separated the stratified water column in the measurement section from the water in the rest of the flume. Incidentally, the rest of the flume could have been left dry; however the rest of the flume was filled with fresh water to the same water depth as in the measurement section to remove the horizontal load on the bulkhead.

The two-layer stratified water column in the measurement section was created in the following way. First, saturated brine was created by adding sodium chloride $(\mathrm{NaCl})$ to water from the labs reservoir. The brine was then diluted in four storage tanks to the desired concentration and blue food dye was added. The four storage tanks were placed at the side of the flume and could contain a total of $24 \mathrm{~m}^{3}$ of salt water. The salt water was circulated between the four storage tanks with submersible pumps to ensure a uniform salinity and color. Fresh water from the labs reservoir was pumped into the measurement section to the desired depth of the top layer. Then salt water from the storage tanks was injected at the bottom at both ends of the measurement section through a slit - initially at a low flow rate, but as the bottom layer developed the injection flow rate was increased. The time to inject the bottom layer was approximately 2 hours. 
The salinity profiles were measured with two two-electrode conductivity meters and reference temperatures at two locations (approximately at $L / 3$ and $2 L / 3$, where $L=26.74 \mathrm{~m}$ is the length of the measuring section). Both salinity profiles were measured by moving the salinity probes vertically down through the water column and recording the elevation of the salinity probe with a linear potentiometer. The salinity profiles were only measured while the salinity probes were being moved vertically down since in this situation the electrodes are unaffected by their housing. The salinity probes were calibrated against a Wissenschaftlich-Technische Werkstätten GmbH Cond 3310 Conductivity Meter (Serial No 09080339) that report practical salinity according to international oceanogrphic tables (IOT). In the given salinity and temperature range, the reference salinities were determined with an accuracy of $+/-0.1 \mathrm{psu}$ (practical salinity unit). Density profiles were derived from the measured salinity profiles using algorithms for computation of fundamental properties of seawater as given in (Fofonoff and Millard Jr. 1983) in the in the oceanographic standard range (sometimes called "Neptunian" range of properties).

The model bridge pier substructures had, prior to the establishing of the stratified water column, been mounted under the towing carriage that runs on two rails mounted on top of the measurement section on each side of the flume. The models were attached through a sandwich structure with two force gauges and a support frame (see Fig. 2). The force gauges of type DHI206/3C, calibrated independently and checked after assembly of the sandwich structure, were able to measure the two horizontal components; the sandwich structure allowed the model to be rotated around the vertical in three discrete angles $\left(5^{\circ}, 10^{\circ}\right.$ and $\left.15^{\circ}\right)$ besides normal incidence without changing the orientation of the measured forces; and the support frame allowed adjustment of the model in the vertical direction whereby a small clearance, less than $5 \mathrm{~mm}$, between the bottom of the model and the flume bottom was established. Current around the model bridge pier was 
simulated by moving the carriage from one end of the measuring section to the other end at a prescribed speed. The speed and position of the carriage was measured with a SICK DME2000 laser distance meter. A typical run with the carriage starting from rest had three stages: acceleration, constant velocity and deceleration. The length of each stage was approximately $1 \mathrm{~m}$, $18 \mathrm{~m}$, and $1 \mathrm{~m}$ respectively. Total length of one run was thus approximately $20 \mathrm{~m}$, which allowed a safety margin of about $3 \mathrm{~m}$ to the bulkheads at either end of the measuring section.

The electric output of the measurement equipment was connected to a digital recording system for data storage. Two kinds of measurements were performed: hydrodynamic loads on the model bridge pier during a carriage run, and density profile measurements in between carriage runs once the potential differences had leveled out after approximately 20 minutes. Uniformity of the density profile was checked by measuring two profiles with some period of time between at each of the two locations. A typical test consisted of a number of carriage runs and a number of density profile measurements. Hydrodynamic loads where also measured for a non-stratified water column (fresh water). In these tests no density profile measurements were performed.

\section{Test conditions}

Current was simulated in the physical model experiments by dragging the model bridge pier through an ambient water column. This limits the test conditions to uniform current over the water depth. Furthermore, the simulated current is without background turbulence. Hence, inherently it is assumed that individual contributions, like the mixing from the natural current turbulence and the mixing from the large-scale turbulence generated around the bridge pier, may be treated separately. Table 1 gives the test conditions for the experiments. Two kinds of tests were performed: 1) hydrodynamic loads in a non-stratified water column, and 2) vertical mixing 
of a two-layer stratified water column.

Hydrodynamic loads on the bridge pier in a non-stratified water column was measured for 2 water depths (Pier 1 and Pier 2), 10 carriage speeds and three current angle of attack (zero incidence, $5^{\circ}, 10^{\circ}$ and $15^{\circ}$ relavtive to the major axis of the bridge pier). Flow around a streamlined body depends on the Reynolds number and the relative surface roughness $d_{50} / D$. The Reynolds number is given by:

$$
\operatorname{Re}=\frac{D U}{v}
$$

where $D$ is width of the streamlined body (the diameter of a circular cylinder), $U$ is the current velocity, and $v$ is the kinematic viscosity. Surface roughness limits the effect of the Reynolds number. For rough circular cylinders with $d_{50} / D$ approximately larger than $10^{-3}$ (see (Achenbach and Heinecke 1981) and (Hoerner 1965, p3-10)) the lower transition, supercritical and upper transition flow merge into one narrow region at a low Re-number. Also, the change in the drag coefficient (i.e. drag force) between the subcritical and transcritical regime is significantly reduced for such rough circular cylinders. The relative surface roughness, $d_{50} / D$, applied to the model bridge piers (elliptic cylinders) was larger than $10^{-3}$. It is therefore assumed that the effect of the Reynolds number was limited in the experiments.

Vertical mixing was studied for two water depths (Pier 1 and Pier 2), four carriage speeds, three current angles of attack (zero incidence, $10^{\circ}$ and $15^{\circ}$ ) and one level of stratification. The interface of the stratified water column was positioned in the middle of the water column irrespective of the water depth. The densimetric Froude number is a governing model law for kinematic similarity in stratified flows. The densimetric Froude number is given by: 


$$
F r=\frac{U}{\sqrt{g \frac{\Delta \rho}{\rho} h}}
$$

where $U$ is the current velocity, $g$ is gravity, $\rho$ is the density and $h$ is the water depth.

Table 1 includes the range of $F r$ and $R e$ covered by the experiments. Note that the Densimetric Froude number changes during a test as the two layers are mixed

\section{Simulations}

In continuation of the model scale experiments a number of numerical simulations were performed. These had the aim of supporting the findings of the physical experiments and to clarify some uncertainties of the experiments. This involved assessing the possible scale effects, confirming the variation of the drag coefficients for low flow velocities, and evaluating the background mixing without the bridge piers in a shear flow.

\section{Navier-Stokes equations}

The numerical method was based on a finite volume discretisation of the Navier-Stokes equations on a collocated grid arrangement. The general form of the Navier-Stokes equations was formulated as the continuity equation:

$$
\frac{\partial u_{i}}{\partial x_{i}}=0
$$

and the momentum equation:

$$
\frac{\partial \rho u_{i}}{\partial t}+\frac{\partial \rho u_{i} u_{j}}{\partial x_{j}}=-\frac{\partial p}{\partial x_{i}}+g_{j} x_{j} \frac{\partial \rho}{\partial x_{i}}+\frac{\partial}{\partial x_{j}} \mu\left(\frac{\partial u_{i}}{\partial x_{j}}+\frac{\partial u_{j}}{\partial x_{i}}\right)
$$

where $\rho$ is the density of the fluid, $u_{i}$ is the Cartesian velocity vector $u_{i}=(u, v, w), p$ is the 
excess pressure, $g_{j}$ is the $j^{\text {th }}$ component of the gravitational vector, $\mu$ is the dynamical viscosity, $t$ is the time, and $x_{i}$ are the Cartesian coordinates.

\section{Turbulence modelling}

For high Reynolds number flows the turbulent fluctuations may not be resolved directly by the computational grid. Therefore a turbulence model must be introduced to account for the effects of the turbulent fluctuations. For the present simulations a Large Eddy Simulation (LES) model has been applied that allows for a direct simulation of the large scale turbulent fluctuations while the LES model adds the effect of the small scale turbulent fluctuations. The theory of LES modelling assumes that the smallest scales of motions are iso-tropic and serve mainly to drain energy from the larger scales and can therefore be modelled by an approximation. On the other hand the large-scale motions which contain most of the energy and are responsible for most of the transporting and mixing should be modelled directly.

For separating the large scales of motion from the small scales of motion an averaging process is introduced in terms of a filter. One characteristic of the filter is the filter width, $\Delta$. Any scales larger than $\Delta$ will be resolved and thereby remain in the filtered flow field while scales smaller than $\Delta$ (Sub-Grid-Scale, SGS) will be modelled by an SGS model.

The implementation introduced in the applied CFD model (CFD: Computational Fluid Dynamics) and summarised in the following is described in (de Villiers 2006) and (Christensen 2006). The LES model is based on a spatial filtering of the Navier-Stokes equations. A top-hat filter is applied where the computational grid is used as the filter. The filtered Navier-Stokes equation reads: 


$$
\rho \frac{\partial \bar{u}_{i}}{\partial t}+\rho \frac{\partial \overline{u_{i} u_{j}}}{\partial x_{j}}=-\frac{\partial \bar{p}}{\partial x_{i}}+g_{j} x_{j} \frac{\partial \bar{\rho}}{\partial x_{i}}+\frac{\partial}{\partial x_{j}} \mu\left(\frac{\partial \bar{u}_{i}}{\partial x_{j}}+\frac{\partial \bar{u}_{j}}{\partial x_{i}}\right)
$$

where overbar denotes a filtered quantity. The second term on the left hand side in equation (13) is split up into two terms as:

$$
\frac{\partial \overline{u_{i} u_{j}}}{\partial x_{j}}=\frac{\partial \bar{u}_{i} \bar{u}_{j}}{\partial x_{j}}+\left(\frac{\partial\left(\overline{u_{i} u_{j}}-\bar{u}_{i} \bar{u}_{j}\right)}{\partial x_{j}}\right)
$$

The first term on the right hand side is simulated directly while the second term is moved to the right hand side of eq. (13) and must be modelled. This term is also referred to as the subgrid scale Reynolds stress:

$$
\tau_{i j}^{s}=-\rho\left(\overline{u_{i} u_{j}}-\bar{u}_{i} \bar{u}_{j}\right)
$$

Equation (15) is called the closure problem for which a model must be applied. If no model is applied, resolved turbulent kinetic energy can only dissipate due to the physical viscosity and the artificial numerical viscosity. This will often lead to a too slow dissipation of energy giving too high turbulence levels. Furthermore, the artificial numerical dissipation depends on the resolution, the numerical discretisation, and the algorithm and is normally not known, which adds uncertainty to the solution. Therefore, a clear definition of how the excess energy should be dissipated is important even in cases where the turbulence is not of main interest. This model is referred to as a sub-grid scale model (SGS model).

A number of different sub-grid scale models have been proposed. Many of these are based on the Smagorinsky SGS model. This is an eddy viscosity model that is closely connected to the strain rate and the grid size. The sub-grid scale stresses given in equation (15) are modelled as: 


$$
\begin{aligned}
& \tau_{i j}^{s}=\frac{1}{3} \tau_{k k}^{s} \delta_{i j}=2 \mu_{t} \bar{S}_{i j}, \\
& \bar{S}_{i j}=\frac{1}{2}\left(\frac{\partial \bar{u}_{i}}{\partial x_{j}}+\frac{\partial \bar{u}_{j}}{\partial x_{i}}\right)
\end{aligned}
$$

where $\mu_{t}$ is the eddy viscosity given as:

$$
\mu_{t}=\rho\left(C_{s} \Delta\right)^{2}|\bar{S}|
$$

where $\Delta$ is the filter length scale and $|\bar{S}|=\left(2 \bar{S}_{i j} \bar{S}_{i j}\right)^{1 / 2} . C_{s}$ is the Smagorinsky constant that is generally in the order of 0.065 to 0.2 . For the present simulations it was set to 0.1 however the optimal value can vary from case to case.

The Smagorinsky model may be improved by adding a history effect, described by a transport equation for one or more of the sub-grid turbulence characteristics to the model. By introducing a transport equation for the turbulent kinetic energy, $k$, we get the $k$-equation model.

The sub-grid scale stresses given in Eq. (16) were modelled based on the $k$-equation for the sub-grid scale turbulence:

$$
\begin{gathered}
k_{s g s}=-\frac{1}{2}\left(\overline{u_{i} u_{i}}-\bar{u}_{i} \bar{u}_{i}\right) \\
\frac{\partial k_{s g s}}{\partial t}+\bar{u}_{j} \frac{\partial k_{s g s}}{\partial x_{j}}=-\frac{1}{\rho} \tau_{i j} \frac{\partial \bar{u}_{i}}{\partial x_{j}}-C_{\varepsilon} k_{s g s}^{3 / 2}+\frac{\partial}{\partial x_{j}}\left(\left(v+v_{t} / \sigma_{k}\right) \frac{\partial k_{s g s}}{\partial x_{j}}\right)
\end{gathered}
$$

The eddy viscosity was found according to:

$$
v_{t}=\rho C_{k} \sqrt{k_{s g s}} \Delta
$$

where $C_{k}$ is a coefficient, which in homogeneous, isotropic turbulence has been found to be in the order of 0.05 to 0.065 , (Yoshizawa 1986) and (Menon et al. 1996). From this the sub-grid scale stresses can be found using a viscosity concept as follows: 


$$
\begin{aligned}
& \tau_{i j}^{s}=\frac{1}{3} \tau_{k k}^{s} \delta_{i j}=2 \rho v_{t} \bar{S}_{i j}, \\
& \bar{S}_{i j}=\frac{1}{2}\left(\frac{\partial \bar{u}_{i}}{\partial x_{j}}+\frac{\partial \bar{u}_{j}}{\partial x_{i}}\right)
\end{aligned}
$$

Because the spatial resolution of the model is high, it is assumed that the scales of motions responsible for the buoyancy mixing are resolved by the model. Therefore no buoyancy effects are included in the SGS model.

\section{Mixing Formulation}

The mixing model was based on an approach where the mixture of two densities was seen as a whole instead of two separate fluids. The two fluids were defined by a passive scalar where a value of 0 denoted the first fluid and a value of 1 denoted the second fluid. Any scalar value between 0 and 1 represented a mixture of the two fluids.

The densities of the two fluids were defined by the value of the phase fraction, $\alpha$. This gives the following properties of the mixture: The mixture density was defined as:

$$
\rho_{m}=\alpha \rho_{1}+(1-\alpha) \rho_{2}
$$

and the mixture pressure was defined as:

$$
P_{m}=\alpha P_{1}+(1-\alpha) P_{2}
$$

The phase fraction scalar, $\alpha$, was implemented by a transport equation give as:

$$
\rho \frac{\partial \alpha}{\partial t}+\rho \frac{\partial \alpha u_{i}}{\partial x_{j}}=\frac{\partial}{\partial x_{j}} \sigma_{t} \mu\left(\frac{\partial \alpha}{\partial x_{j}}\right)
$$

where $\sigma_{t}$ is the turbulent Smith number.

\section{Boundary Conditions}


A number of basic boundary conditions were applied such as a fixed value (Dirichlet) inlet condition for velocity and fixed gradient (Neumann) inlet conditions for pressure. These boundary conditions are described as part of the general model setup. However, the wall boundary conditions require a more detailed description in terms of a wall function and the turbulent inlet condition.

\section{Turbulent Wall Properties - Wall Functions}

In order to reproduce the correct separation point on the bridge pier, the near-wall flow and shear stresses must be simulated. This requires a very fine resolution near the wall with a grid size in the order of $y^{+}=1$, where $y^{+}=y u_{\tau} / v$ and $u_{\tau}$ is the friction velocity. This will be computationally expensive in terms of long simulation times due to small grid sizes and thereby corresponding small time steps. As the actual boundary layer flow was not of interest in itself but merely the effect of the flow, the solution was to apply a wall function in the near wall cells. Hereby, the near wall cells can be placed at a distance of $30<y^{+}<100$ and the flow in this cell was then described by a wall function, see e.g. (Sagaut 2006).

Several different LES wall treatments have been proposed in the literature where most models attempt to predict the wall shear stress. An overview is given in (Sagaut 2006) and (de Villiers 2006). A group of models are characterised as equilibrium stress models. The basis of these models is that the stresses in the boundary layer are assumed to be in an average or instantaneous equilibrium. If this is the case, some form of the logarithmic law of the wall should be applicable in the near wall region. A widely used model imposes the logarithmic law in the near wall region by calculating the shear stress as: 


$$
\frac{\bar{u}_{0}}{u_{\tau}}=\frac{1}{\kappa} \log \left(\frac{y_{0} u_{\tau}}{v} E\right)
$$

where $u_{\tau}=\sqrt{\tau_{w} / \rho}$ is the friction velocity, $\bar{u}_{0}$ is the mean velocity at $y=y_{0}, E$ is a wall function constant, and $\kappa$ is the von Karman constant.

The model imposes the logarithmic law which leads to the assumption that the first point off the wall is placed in the logarithmic layer (typically $y^{+} \geq 30 \quad$ ). Some limitations are associated with this method, i.e., the required distance of $y^{+} \approx 30$, and the inability to account for non-equilibrium effects. Other more advanced models may compensate for these limitations. A commonly used model is the Spaldings law which is a fit of the laminar, buffer, and logarithmic region of an equilibrium boundary layer:

$$
y^{+}=u^{+}+\frac{1}{E}\left[e^{\kappa u^{+}}-1-\kappa u^{+}-\frac{1}{2}\left(\kappa u^{+}\right)^{2}-\frac{1}{6}\left(\kappa u^{+}\right)^{3}\right]
$$

where $\kappa=0.42$ and $E=9.1$ are constants, $y^{+}=y_{0} u_{\tau} / v$ and $u^{+}=\bar{u}_{0} / u_{\tau}$. When substituting the known values of $y_{0}$ and $\bar{u}_{0}$ next to the wall the friction velocity, $u_{\tau}$ can be found by using an iterative procedure and thereby providing the wall shear stress.

The distribution of the turbulent kinetic energy near the wall was implemented according to (de Villiers 2006):

$$
\begin{array}{ccc}
k=0 & \text { for } & y^{+} \leq 20 \\
\frac{\partial k}{\partial y}=0 & \text { for } & y^{+}>20
\end{array}
$$

\section{Turbulent inlet condition}

The generation of the turbulent inlet quantities for LES is a well known problem where 
several methods have been proposed in the literature. One option is a pre-computed database where the inlet is assumed to be positioned at the outlet of a long channel. The flow in this case is computed beforehand and the result is stored in a database in terms of the inlet conditions to the final simulations. Another method is based on mapping the velocities and turbulent quantities from a plane inside the domain and back to the inlet. Hereby the first part of the domain is used to develop the turbulent characteristics to be mapped back to the inlet. This method is applied for the simulations where a current profile is needed.

\section{Model setup and conditions}

The model domain covered an upstream distance of $40 \mathrm{~m}$ and a downstream distance of $100 \mathrm{~m}$ or $500 \mathrm{~m}$ depending on the objective of the individual simulation. Simulations with uniform density for calculation of drag coefficients were performed with the short domain of $100 \mathrm{~m}$, while the simulations with density stratification and mixing were performed with the $500 \mathrm{~m}$ domain in order to resolve the downstream mixing process. A distance of $60 \mathrm{~m}$ was included on both sides of the pier in the transversal direction. The depth was $28 \mathrm{~m}$ corresponding to the deepest location across the Fehmarn Belt. All simulations were made at prototype (full) scale. Figure 3 presents the two model domains (including bridge pier 1 for illustration) with a downstream distance of $100 \mathrm{~m}$ and $500 \mathrm{~m}$.

The computational grid was set up to give a sufficient resolution to resolve the characteristic flow features involved in the mixing process, while at the same time the total number of grid cells was kept at a level where the simulations could be finalised within a reasonable time. Some of the considerations on which the computational mesh was based are:

- The velocity gradient in the boundary layer around the structure can be resolved when the 
nearest horizontal grid extension is in the order of 1-2 roughness heights. For the present structure, this gives a roughness of $5-15 \mathrm{~cm}$ and a resolution of $0.05 \mathrm{~m}$.

- The vertical and horizontal extension of the horseshoe vortex is in the same order of magnitude as the displacement depth. The displacement depth will be approximately 10 $\%$ of the depth of the upper layer $(\approx 15 \mathrm{~m})$. This means that the horseshoe vortex can be resolved with cells of $10-30 \mathrm{~cm}$.

- The horizontal size of the wake is approximately half the width of the structure $(\approx 5 \mathrm{~m})$. The wakes can be resolved with $0.5 \mathrm{~m}$ large grid cells.

- The plinth is $2-5 \mathrm{~m}$ high. Here the resolution is $\Delta z=\Delta x \approx 0.25-0.5 \mathrm{~m}$.

- Internal waves will not be the limiting factor for the grid resolution.

An example of the computational mesh is given in Fig. 4 in terms of bridge pier No. 1. The mesh was set up with the minimum cell size at the pier surface at $0.1 \mathrm{~m}$. The depth was resolved with $0.2 \mathrm{~m}$ cells for the drag simulations and down to $0.1 \mathrm{~m}$ cells for the mixing simulations. The horizontal resolution extending away from the pier started at $0.1 \mathrm{~m}$ at the pier surface and was stretched up to $0.5 \mathrm{~m}$ at a distance of two times the pier length. A further stretching was applied from here on resulting in a maximum horizontal cell size at $1.0 \mathrm{~m}$. The total number of grid cells for the large $500 \mathrm{~m}$ domain was 12.5 million cells.

\section{Results}

\section{Drag forces}

Figure 5 shows the drag coefficients for Pier 1 and 2 elaborated from the experiments and numerical simulations at zero incidence as function of the velocity. The numerical simulations 
were carried out in full scale, hence the velocities are normalized with $\sqrt{g h}$ for comparison with the experimental results. The figure shows that the drag coefficient can be considered constant over a wide range of current speeds. There was a decline in the measured drag coefficient for Pier 1 at small current speeds in the experimental results. The measured drag coefficient were based on a single run with the carriage. Indeed the subsequent tests with stratified water column confirmed that the work scaled with the velocity squared when a larger number of runs where considered. (Castro, Snyder and Baines 1990) showed that drag on an obstacle in stratified flow can be a function of the densimetric Froude number. However, in the present experiments no such dependency was observed. In general, a good agreement was achieved between the numerical simulations and the physical model experiments.

Comparing the drag coefficient for Pier 1 with that of Pier 2 illustrates the effect of the rectangular plinth on top of the elliptical shape. It was seen that the change in the cross-sectional shape of the bridge pier substructure from an ellipse to a rectangle below the water line generally increases the drag coefficient by approximately a factor of 2 in the tested range of flow velocity. This additional drag was associated to the rectangular plinth, which is positioned at the water surface. This is an important observation to have in mind when the results of the mixing efficiency was treated.

The current direction was seen to affect the drag in terms of a larger drag coefficient when the angle was changed to be different from $0^{\circ}$, as indicated in Fig. 5. Again a good agreement was found between experiments and simulations, where the same variation in drag was found going from $0^{\circ}$ to $15^{\circ}$.

Figure 6 shows the variation in the drag force with the current angle of attack for pier 1. The mean drag force coefficient increases with increasing current angle of attack, and the standard 
deviation highlight that the drag force was essentially constant over the range of velocities tested. The pier experienced a mean lift force when the current angle of attack was not equal to zero. This lift force induced an additional drag force. The induced drag force coefficient may be assumed to be related to the lift force coefficient as: $C_{D i}=C_{D, \alpha}-C_{D, \alpha=0}=$ constant $\cdot C_{L}^{2}$, see (Hoerner, 1965, p7-2). The lift coefficient for a flat and thin plate using potential flow theory can be shown to equal $C_{L}=2 \pi \cdot \sin (\alpha)$, see (Hoerner, 1975, p2-8). Hence using the concept of lift induced drag one may assume that the induced drag coefficient should follow a curve given by: $C_{D i}=$ constant $\cdot \sin ^{2}(\alpha)$. This was indeed the case as shown in Fig. 6. The constant was found by least square method to be 3.46.

\section{Mixing efficiency}

The mixing efficiency was determined as the bulk flux Richardson number as defined in the Methods section. The change in potential energy, i.e., the redistribution of density, was determined based on the density profile measurements. Figure 7 shows an example of the measured density profiles for a single test, namely $h=0.571 \mathrm{~m}, U=0.21 \mathrm{~m} / \mathrm{s}$ and $\Delta S=10$. In the test six density profiles were measured. The input of kinetic energy (work performed) was practically constant between each of the density profiles given identical carriage velocity and length travelled by the carriage.

The figure shows that the density increased in the upper part of the water column, a minor decrease in the lower part, and a lowering of the interface along with a slight decrease in the slope of the density profile at the interface.

A small correction is applied to the density profiles so the depth averaged density does not change which ensures conservation of mass. The depth averaged density before correction was for 
this case $1002.6 \mathrm{~kg} / \mathrm{m} 3$ with a standard deviation of $0.01 \mathrm{~kg} / \mathrm{m}^{3}$. The potential energy has been calculated for each of the six density profiles in Fig. 7 as detailed in the Methods section. The change in potential energy realative to the initial density profile is plotted in Fig. 8 as function of the cummulative input of turbulent kinetic energy (i.e. the work performed when the bridge pier is dragged through the ambient water column). Figure 8 shows a linear relationship between the change in potential energy and the cummulative input of turbulent kinetic energy. This linear relationship has been indicated on the figure. The slope of straight line equals to the bulk flux Richardson number or the mixing efficieny. For this test the mixing efficiency was found to be $R_{f}^{T}$ $=0.054$. Note, the change in potential energy will not always vary linearly with the work done; when the fluid is fully mixed, the additional potential energy change will be zero. (Rehmann and Koseff, 2004, Fig. 2) illustrates the effect on $R_{f}^{T}$. For this reason the potential energy change was intentionally kept small in the experiments.

The numerical simulations were performed with a flow with current shear and as such the natural interface mixing was included. The background mixing was quantified by a simulation that was carried out without the bridge pier included in the model domain. This showed a natural mixing of $\approx 0.5 \%$ which is about one order of magnitude smaller than the bridge pier induced mixing for the high current velocities. This background mixing was extracted before the results were compared to the experimental results.

In Fig. 9 the determined mixing efficiency for Pier 1 and 2 has been plotted as a function of the current velocity normalized with $\sqrt{g h}$. We see that the mixing efficiency was generally in the order of $5 \%$ to $6 \%$ for large velocities and at the lowest velocities tested. However, at a current velocity in the order of $0.1 \mathrm{~m} / \mathrm{s}(U / \sqrt{g h}=0.04)$, a peak in the mixing efficiency was observed. This variation was observed both in the experiments and the numerical modelling and causes for 
this increase are explored in the Discussion section.

When the two pier shapes are compared, the same trend is seen in terms of a mixing efficiency of about $5 \%$ to $6 \%$ for the high velocities above $0.15 \mathrm{~m} / \mathrm{s}$ and an increasing mixing efficiency for lower velocities. However, it is seen that the maximum mixing efficiency for Pier 1 was $\approx 12 \%$ while for Pier 2 it was $\approx 23 \%$. This may lead to the conclusion that Pier 2 (pure ellipse) gives a higher mixing. However, when looking into the data the produced energy (or the work performed in terms of the in-line force) gives an explanation on the difference in mixing. As seen in equation (4) the produced energy, $W$, goes into the denominator of the bulk flux Richardson number. For Pier 1 the in-line force was approximately $1.5-2$ times higher than for Pier 2 due to the rectangular plinth near the water surface. Since the mixing efficiency for Pier 1 was correspondingly smaller than for Pier 2 the change in potential energy, $\Delta E_{p o t}$, in the nominator of equation (4), was almost identical for the two pier shapes. An explanation for this is that the additional input of energy in terms of the higher drag force for Pier 1 was situated near the water surface at the rectangular plinth. This might only have little effect on the actual mixing at the stratification, which took place approximately $0.3 \mathrm{~m}$ below the water surface $(15 \mathrm{~m}$ in full scale).

The current angle of attack was only studied for Pier 1. In this case the mixing efficiency was approximately constant irrespective of the current angle of attack. The measured mixing effeciency, $R_{f}{ }^{T}$, was $0.063,0.076$, and 0.079 for $\alpha=0^{\circ}, 10^{\circ}$ and $15^{\circ}$, respectively.

\section{Discussions}

The physical scale experiments were designed to minimize scale effects. Scale effects may occur since the experiments are performed according to a Froude scaling while the Reynolds 
number is not maintained constant in model scale and prototype. In the section on the physical model experiments this topic was discussed and it was argued that no significant scale effects would occur. To support this argument the numerical modelling was performed in prototype measures and the results should correspond to those found in the physical experiments in the case that no scale effects were included. Based on the consistency between the results of the model scale experiments and the prototype numerical simulations, it was concluded that no significant scale effects were present.

The physical experiments showed a slight decrease in the drag coefficients for low current velocities. This was assumed to be due to the measuring accuracy, which was important for the measurements of small drag forces. For determining the produced energy, corresponding to the drag force on the bridge piers, the measured drag force was applied. However, for the low velocities a constant drag coefficient was applied together with the current (carrige) velocity to calculate the drag force. This constant drag force was determined based on the drag force measurements in uniform flow. In order to confirm this assumption of a constant drag coefficient also for low flow velocities, the numerical simulations covered these low flow velocities. As seen in Fig. 5 the numerical simulations predicted a drag coefficient that compared well with the measured coefficient for the high flow velocities. For the low flow velocities the numerical simulations supported the assumption of a constant drag coefficient.

Regarding the mixing efficiency, the bulk flux Richardson number, $R_{f}^{T}$, was found to be in the order of $5 \%$ to $6 \%$. For a certain current velocity an increase in the mixing efficiency was seen for both investigated bridge piers. In the following we made an attempt to link our results to the findings in (Linden 1980; Turner 1968, 1973). They found two destinct regions for the entrainment rate dependent on the overall Richardson number. Before going into details we need 
a relation to determine the entrainment velocity similarly as done in (Linden 1979 and Jackson and Rehmann (2003)). Therefore, considering a unit area of the two-layered water column in Fig. 10. The density of the upper layer before mixing is chosen as the reference density, $\rho_{R}=\rho_{u}$. The density of the lower layer is then given by $\rho_{l}=\left(1+\Delta_{l}\right) \cdot \rho_{R}$, where $\Delta=\Delta_{l}=\left(\rho_{l}-\rho_{R}\right) / \rho_{R}$. Conservation of mass gives:

$$
\begin{aligned}
\rho_{M}\left(y_{1}+y_{2}\right) & =\rho_{u} y_{1}+\rho_{l} y_{2} \\
& =\rho_{R} y_{1}+(1+\Delta) \rho_{R} y_{2} \\
\Rightarrow \quad \rho_{M} & =\rho_{R}\left(1+\Delta \frac{y_{2}}{y_{1}+y_{2}}\right)
\end{aligned}
$$

where $\rho_{\mathrm{M}}$ is the density of the mixed fluid. The change in potential energy, per unit area which is equal to the work needed for the mixing process, is:

$$
\Delta E_{p o t}=\left(E_{p o t}\right)_{\text {affer }}-\left(E_{\text {pot }}\right)_{\text {before }}=\frac{1}{2} \Delta \rho_{R} g y_{1} y_{2}
$$

This result can be found by integrating the density profiles before and after mixing, or directly, if one interpret the result as the work done by raising the excess mass, $\Delta \rho_{R} y_{2}$, the center of gravity distance $1 / 2 \mathrm{y}_{1}$.

In the present study, mixing was due to external turbulence in the two layers. First, consider a two-layered water column with turbulence in the upper layer as illustrated in Fig. 11. Turbulence in the upper layer erodes the interface at a rate $V_{E}(\mathrm{~m} / \mathrm{s})$ resulting in a lowering of the interface. The entrained denser water from below gains potential energy by being lifted (by turbulent diffusion) the distance $1 / 2 y$ on average, yielding a potential energy per unit time which amount to:

$$
\frac{d}{d t}\left(E_{p o t}\right)=\frac{\Delta E_{p o t}}{\Delta t}=\frac{1}{2}\left(\Delta_{l}-\Delta_{u}\right) \rho_{R} V_{E} g y=\frac{1}{2} \Delta \rho V_{E} g y, \quad\left[\frac{J}{m^{2} s}\right]
$$


where index $1=$ lower and $\mathrm{u}=$ upper layer.

Referring to the total mixing sketched Fig. 10 we come to the same end result independently on whether the mixing originates from turbulence in the upper or lower layer. Therefore, equation (31) must hold true for mixing due to turbulence in the lower layer as well. When turbulence is present in both layers the level of the interface does not change during the mixing process. The erosion rate can thus in the present case not be determined based on the lowering of the interface.

In order to link our results to earlier findings we now examine the definitions in (Turner 1968). He states that the entrainment velocity, $V_{E}$, always can be defined as the rate of mixing in one direction (say from top to bottom) across the interface, whether or not the upper layer is stirred:

$$
V_{E}=\frac{-h}{C_{2}-C_{1}} \frac{d C_{2}}{d t}
$$

Here, $C_{1}$ and $C_{2}$ is the concentrations of salt in the upper and lower layer, respectively; and the layers be of equal fixed depths h. The total rate of change of the concentration difference will be doubled if the stirring is symmetrical, since $V_{E}$ is unchanged. Therefore, the above definition of $V_{E}$ continues to hold but may now also be expressed in terms of the rate of change of concentration in the upper layer

$$
V_{E}=\frac{h}{C_{2}-C_{1}} \frac{d C_{1}}{d t}
$$

(Fernando 1991), referring to (Turner 1968), replaced the concentration with the density of the fluid and note that entrainment velocity can be expressed in terms of change in the density difference (adding the above two equations together) 


$$
V_{E}=\frac{1}{2} \frac{h}{\rho_{1}-\rho_{2}} \frac{d\left(\rho_{1}-\rho_{2}\right)}{d t}=\frac{1}{2} \frac{h}{\Delta \rho} \frac{d(\Delta \rho)}{d t}
$$

In the present case the entrainment velocity can be calculated directly as the gradient of the density difference with respect to time using:

$$
\frac{d(\Delta \rho)}{d t}=\frac{d(\Delta \rho)}{d x} \frac{d x}{d t}=\frac{\Delta(\Delta \rho)}{L^{\prime}} U
$$

where $L^{\prime}$ is the length traveled between two successive density profile recordings. Or as will be shown later, the entrainment velocity may be inferred from the measured change in potential energy using equation (31).

(Fernando 1991) states that the entrainment velocity in the absence of molecular diffusion is usually written as

$$
\frac{V_{E}}{u_{1}} \propto R i_{0}^{-n}
$$

Where $n$ is a constant (over a certain range of $R i_{0}$ ) and $R i_{0}$ is the overall Richardson number:

$$
R i_{0}=g \frac{\Delta \rho}{\rho} \frac{l_{1}}{u_{1}^{2}}
$$

in which $l_{1}$ and $u_{1}$ are characteristic length and velocity scales of the turbulence. The challenge is to define $l_{1}$ and $u_{1}$ so that comparison with different flows is possible. However, (Turner 1973) note that as long as all the scales used are genuine flow parameters then the choice of $l_{1}$ and $u_{1}$ affects only the magnitude but not the slope of $V_{E} / u_{1}$ against $R i_{0}$ on a logarithmic plot.

The length and velocity scales, $l_{1}$ and $u_{1}$, were in (Turner 1968) defined as, the integral length scale and root mean square value of the horizontal component of the turbulent velocity, 
respectively (see also (Turner 1973)). (Linden 1980) measured mixing produced by dropping a horizontal grid through a sharp density interface and defined the overall Richardson number based on the mesh length and the terminal velocity of the grid in fresh water. A great number of experiments have been carried out where turbulence is generated by towing a bi-planar grid horizontally through an ambient stratified water column (see e.g. (Britter et al. 1983) and (Rehmann and Koseff 2004)). In this case the overall Richardson number is given by the mesh size and the speed at which the grid is towed. (Holford and Linden 1999) towed a rake of vertical bars (mono-planer grid) through an ambient stratified water column. They used the square root of the bar width multiplied with the bar spacing as the turbulent length scale. The velocity scale used was the tow speed with corrections for the grid solidity (bar width divided by the bar spacing).

The turbulence in the wake of an obstacle like a bridge pier in a non-stratified water column scales with the flow velocity and width of the structure. Therefore, one obvious choice for the characteristic length and velocity scale in the present case is the width of the bridge pier and the carriage speed, respectively.

$$
u_{1}=U \text { and } \quad l_{1}=D
$$

The length scale for instance does not necessaryly resemble the integral length scale of the horizontal turbulent velocity. It could be argued that a length scale equal to half a diameter, $1 / 2 D$, would be just as reasonable length scale as the diameter. It would not change the slope of the curve of $V_{E} / u_{1}$ against $R i_{0}$ on a logarithmic plot, but it would shift the curve along the axis for $R i_{0}$. The overall Richardson number based on the equation (38) is

$$
R i_{0}=g \frac{\Delta \rho}{\rho} \frac{D}{U^{2}}
$$


The entrainment velocity can be found using equation (31).

$$
\frac{V_{E}}{U}=\frac{2}{g h L^{\prime}} \frac{\Delta E_{p o t}}{\Delta \rho}
$$

since $\Delta t=L^{\prime} / U$ and the change in potential energy is twice that in equation (31) since turbulence is present in both layers.

Figure 12 shows a logarithmic plot of $V_{E} / U$ against $R i_{0}$. Furthermore, two of the typical values of $n$, namely 0 and $3 / 2$ has also been indicated. As mentioned earlier, the choice of characteristic length and velocity scale may change the magnitude of $V_{E} / U$ against $R i_{0}$ on a logarithmic plot, however the slopes are not affected. If the two data points for Pier 1 with the lowest $R i_{0}$ are ignored, then present data suggest that there are essentially two regions. The first region occurs at low $R i_{0}$ suggest a fundamental relationship with $n=0$ while the second region at higher $R i_{0}$ suggest a fundamental relationship with $n=3 / 2$.

Interestingly the present choice of turbulent scales splits the two regions at roughly the same values of $R i_{0}$ as in (Turner 1973). (Turner 1973) describes the two regions in the following way: As $R i_{0} \rightarrow 0$ the buoyancy effect becomes negligible and $V_{E}$ is a constant fraction of $u_{1}$. The functional form of $V_{E} / U$ for high $R i_{0}$ depends on molecular diffusivity. This is seen in ((Turner 1973), Fig. 9.3) by the rates of mixing are different with temperature or salinity difference across the interface, $V_{E} / U \propto R i_{0}^{-1}$ (heat) and $V_{E} / U \propto R i_{0}^{-3 / 2}$ (salt). For higher $R i_{0}$ the gravity is increasingly important, so denser water lifted into the upper layer is returned to the lower layer before being mixed with the upper layer. The shift between the two regions was approximately the same as reported in (Linden 1980) as well where the shift is reported to be at $R i_{0} \sim 1-2$. (Rehmann and Koseff 2004) studied linearly stratified fluid and 
found two regions for the mixing as well, with the shift at $R i_{0} \sim 1$. The shift between the two regions depend as earlier pointed out on the choice of length and velocity scales. For instance, in our case the shift would move to $R i_{0} \sim 1$ from $R i_{0} \sim 2$ when reducing the length scale from $D$ to $1 / 2 D$.

Returning to the two data points Pier 1 with the lowest $R i_{0}$. In the present context a low $R i_{0}$ is equal to high velocities since the strength of the stratification was kept practically constant throughout the tests. Pier 1 produced a substantial part of the turbulent kinetic energy near the free surface of the water column due to the plinth. This resulted in a higher initial turbulence level and therefore also a higher level of turbulence from this source at the interface. It is therefore likely that the turbulence generated by the plinth was responsible for the increased entrainment rate observed for Pier 1 at low $R i_{0}$ (high velocities) in the experiments.

The experiment focused on determining the bulk flux Richardson number as function of the velocity. The above discussion may be used to formulate a mathematical model for the variation of $R_{f}^{T}$ with respect to $U$. There are two regions: First, a region where the buoyance effects are important so $\frac{V_{E}}{U}=c_{1} \cdot R i_{0}^{-3 / 2}\left(n=\frac{3}{2}\right)$; Secondly, a region where the buoyancy effect is negligible so $\frac{V_{E}}{U}=c_{2}(n=0)$. Here $c_{1}$ and $c_{2}$ are both constants.

The change in potential energy using equation (31) may be written as (where the change is double as double sided stirring occurs)

$$
\Delta E_{p o t}=\frac{d}{d t}\left(E_{p o t}\right) \cdot \Delta t \cdot A=2\left(\frac{1}{2} \Delta \rho V_{E} g \frac{h}{2}\right) \cdot \frac{L}{U} \cdot A=\frac{1}{2} \Delta \rho g h L A \frac{V_{E}}{U}
$$

The work done may be written as: 


$$
W=\frac{1}{2} \rho C_{D} A_{f} U^{2} L
$$

Hence the bulk flux Richardson number is:

$$
R_{f}^{T}=\frac{\Delta E_{p o t}}{W}=\frac{\frac{1}{2} \Delta \rho g h L A \frac{V_{E}}{U}}{\frac{1}{2} \rho C_{D} A_{f} U^{2} L}=A \frac{\Delta \rho}{\rho} \frac{g h}{C_{D} A_{f}} \frac{1}{U^{2}} \frac{V_{E}}{U}
$$

Plugging in the two relationships established for the entrainment rate:

$$
R_{f}^{T}=\left\{\begin{array}{ccc}
A \frac{\Delta \rho}{\rho} \frac{g h}{C_{D} A_{f}} c_{2} \cdot \frac{1}{U^{2}} & \text { for } & R i_{0}<2 \\
A \frac{\Delta \rho}{\rho} \frac{g h}{C_{D} A_{f}} c_{1}\left(g \frac{\Delta \rho}{\rho} D\right)^{-\frac{3}{2}} \cdot U & \text { for } & R i_{0} \geq 2
\end{array}\right.
$$

The model described by the last two lines in Table 2 is shown together with the measured $R_{f}^{T}$ against the carriage speed normalized with $\sqrt{g h}$ in Fig. 9. (Rehmann 2004) developed a similar model as the one outlined in equation (44). (Rehmann 2004) predicts linear relationship for low $R i_{0}$ and inverse-square root relationship for high $R i_{0}$; they also predict $R_{f}^{T} \propto \sqrt{R i_{0}}$ for moderate stratification. Equation (44) can be rewritten in terms of $R i_{0}$ to give $R_{f}^{T} \propto R i_{0}$ for $R i_{0}<2$ and $R_{f}^{T} \propto\left(R i_{0}\right)^{-1 / 2}$ for $R i_{0} \geq 2$, similar to (Rehmann 2004). This support the choice of scales and explanation above.

\section{Conclusions}


This paper presented the results of a study related to the mixing of stratified flow around bridge pier structures in estuarine and ocean environments. The subject of the study was a proposed bridge pier design for the new Fehmarn Belt fixed link between Denmark and Germany. The goal of the study was to gain knowledge about the mixing processes around bridge pier structures and to evaluate the environmental impact of the specific pier designs at hand.

The numerical simulations were carried out in full scale and scaled to model scale for comparison with the experimental results. Further, the numerical simulations were based on a current passing the structure, where as in the experiments a models of two different piers were draged throgh the water. Drag force coefficients estimated from experiments and numerical simulations showed the same overall tendency.

The gain in potential energy was estimated as an increase of density in the upper layer at the expense of a lowering of the interface and decrease of the density in the lower layer. The gain in potential energy was compared to the generation of turbulent kinetic energy by the interaction with the bridge piers, the Bulk flux Richardson number $R_{f}^{T}$. Both physical experiments and numerical simulations showed an enhanced mixing due to the presence of bridge piers at $5 \%$ to 6 $\%$ for realistic prototype current velocities. For low velocities we identified an increased mixing of $12 \%$ to $23 \%$ for the tested pier designs. As part of the numerical simulations the background mixing was $\approx 0.5 \%$ which was not included in the physical experiments. This background mixing was extracted before the results were compared to experimental results.

We found that the data supported that the mixing can be split into two different regions divided by a full Richardson number of $R i_{0} \sim 2$. Support for the division into two regions was found in the literature, such as (Linden 1980; Turner 1968) and others. In one region density plays a major role for the mixing where turbulent fluctuations at the interface of the stratified fluid cannot 
overcome the stabilizing effect of gravity. In the other region the stratification is either low/nonexisting or the turbulent fluctuations are very strong and relatively not affected by gravity. In the analyses here and in the literature the two regions could be identified based on realistic length and velocity scales for turbulence.

\section{Acknowledgements}

The research was partly supported by the Femern Bælt A/S, Fehmarnbelt Fixed Link under the reference number ENV010010 and partly by the FP7-OCEAN- 2011 project "Innovative Multi-purpose offshore platforms: planning, Design and operation", MERMAID, 288710, under the call "Ocean of Tomorrow",

\section{References}

Achenbach, E., and Heinecke, E. (1981). "On vortex shedding from smooth and rough cylinders in the range of Reynolds numbers $6 \times 10^{\wedge} 3$ to $5 \times 10^{\wedge} 6$." Journal of Fluid Mechanics, Cambridge University Press, 109, 239-251.

Arneborg, L., Fiekas, V., Umlauf, L., and Burchard, H. (2007). “Gravity Current Dynamics and Entrainment—A Process Study Based on Observations in the Arkona Basin." Journal of Physical Oceanography, 37(8), 2094-2113.

Britter, R. E., Hunt, J. C. R., Marsh, G. L., and Snyder, W. H. (1983). “The effects of stable stratification on turbulent diffusion and the decay of grid turbulence." Journal of Fluid Mechanics, 127, 27-44.

Castro, I. P., Snyder, W. H., and Baines, P. G. (1990). “Obstacle drag in stratified flow.” Proc. R. Soc. Lond. A, 429, 119-140. 
Christensen, E. D. (2006). "Large eddy simulation of spilling and plunging breakers." Coastal Engineering, 53, 463-485.

Fennel, W., and Sturm, M. (1992). "Dynamics of the western Baltic." Journal of Marine Systems, 3(1-2), 183-205.

Fernando, H. J. S. (1991). "Turbulent Mixing in Stratified Fluids.” Annual Review of Fluid Mechanics, Annual Reviews 4139 El Camino Way, P.O. Box 10139, Palo Alto, CA 94303-0139, USA, 23(1), 455-493.

Fofonoff, N. P., and Millard Jr., R. C. (1983). Algorithms for computation of fundamental properties of saltwater. UNESCO.

Grubert, J. P. (1989). "Interfacial Mixing in Stratified Channel Flows." Journal of Hydraulic Engineering, American Society of Civil Engineers, 115(7), 887-905.

Hoerner, S. F. (1965). “Fluid dynamic drag”. Hoerner Fluid Dynamics, Bricktown New Jersey, 1965.

Holford, J. M., and Linden, P. L. (1999). “Turbulent mixing in a stratified fluid.” Dynamics of atmospheres and oceans, 30, 173-198.

Holmboe, J. (1962). "On the behavior of symmetric waves in stratified shear layers." Geofys. Publik., Geophysica Norvegica, 24, 67-114.

Ivey, G. N., and Imberger, J. (1991). "On the Nature of Turbulence in a Stratified Fluid. Part I: The Energetics of Mixing." Journal of Physical Oceanography, 21(5), 650-658.

Jackson P. R. and Rehmann, C. R. (2003). "Kinematic Effects of Differential Transport on Mixing Efficiency in a Diffusively Stable, Turbulent Flow." J. Phys. Oceanogr., 33, pp. 299-304.

Jakobsen, F., Hansen, I. S., Ottesen Hansen, N.-E., and Østrup-Rasmussen, F. (2010). “Flow 
resistance in the Great Belt, the biggest strait between the North Sea and the Baltic Sea." Estuarine, Coastal and Shelf Science, 87(2), 325-332.

Jürgensen, C. (1989). Entrainment introduced by piers, dams, and ships in a stratified channel flow. Institute of Hydrodynamics and Hydraulic Engineering, Technical University of Denmark.

Lass, H. U., Mohrholz, V., Knoll, M., and Prandke, H. (2008). "Enhanced mixing downstream of a pile in an estuarine flow." Journal of Marine Systems, 74(1-2), 505-527.

Linden, P. F. (1979). "Mixing in Stratified Fluids." Geophys. Astrophys. Fluid Dynamics, Vol. 13 , pp. 3-23

Linden, P. F. (1980). “Mixing across a density interface produced by grid turbulence.” Journal of Fluid Mechanics, 100(4), 691-703.

Menon, S., Yeung, P.-K., and Kim, W.-W. (1996). "Effect of subgrid models on the computed interscale energy transfer in isotropic turbulence." Computers \& Fluids, 25(2), 165-180.

Miller, J. L., and Valle-Levinson, A. (1996). "The Effect of Bridge Piles on Stratification in Lower Chesapeake Bay.” Estuaries, 19(3), 526.

Møller, J. S., and Ottesen Hansen, N.-E. (1997). "Mixing in startified flow caused by obstacles." Journal of Marine Environmental Engineering, 4, 97-111.

Pedersen, F. B. (1986). Environmental Hydraulics: Stratified Flows. Spinger-Verlag, Berlin Heidelberg New York Londaon Paris Tokyo.

Peltier, W. R., and Caulfield, C. P. (2003). "Mixing Efficiency Efficiency in Stratified Shear Flows." Annual Review of Fluid Mechanics, 35, 135-167.

Rehmann, C. (2004). "Scaling for the mixing efficiency of stratified grid turbulence.” Journal of Hydraulic Research, 42(1), 35-42. 
Rehmann, C. R., and Koseff, J. R. (2004). "Mean potential energy change in stratified grid turbulence." Dynamics of Atmospheres and Oceans, 37(4), 271-294.

Rennau, H., Schimmels, S., and Burchard, H. (2012). "On the effect of structure-induced resistance and mixing on inflows into the Baltic Sea: A numerical model study." Coastal Engineering, 60, 53-68.

Rouse, H., and Dodu, J. (1955). "Turbulent diffusion across a density discontinuity." La Houille Blanche, 10(4), 522-532.

Sagaut, P. (2006). Large Eddy Simulation for Incompressible Flows: An Introduction. SpringerVerlag, Berlin Heidelberg New York.

Smyth, W. D., and Winters, K. B. (2003). "Turbulence and Mixing in Holmboe Waves.” Journal of Physical Oceanography, 33(4), 694-711.

Strang E. J., and Fernando, H. J. S. (2001). "Entrainment and mixing in stratified shear flows." Journal of Fluid Mechanics, Cambridge University Press, 428, 349-386.

Trafikministeriet. (1999). Femer bælt-forbindelsen, Forundersøgelser -Resumérapport.

Turner, J. S. (1968). "The influence of molecular diffusivity on turbulent entrainment across a density interface." Journal of Fluid Mechanics, 33(4), 639-656.

Turner, J. S. (1973). Buoyancy Effects in Fluids. Cambridge University Press.

de Villiers, E. (2006). “The Potential of Large Eddy Simulation for the Modeling of Wall Bounded Flows." PhD thesis, Imperial College of Science, Technology and Medicine.

Yoshizawa, A. (1986). "Statistical theory for compressible turbulent shear flows, with the application to subgrid modeling." Physics of Fluids, AIP Publishing, 29(7), 2152-2164. 


\section{Figure Captions}

Figure 1: Generic bridge piers substructures given by the Fehmarn feasibility study (summarized in Trafikministeriet 1999). Full-scale and model dimensions (in square brackets). The frontal projection is for Pier 1 and Pier 2, respectively $A_{f, 1}=0.130 \mathrm{~m}^{2}$ and $A_{f, 2}=0.117 \mathrm{~m}^{2}$ in model scale.

Figure 2: Sketch of the experimental set-up where the carriage towed the structure through an ambient water column and thereby simulated a current.

Figure 3: View of model domain. A) Short model domain for drag simulations and B) Long model domain for mixing simulations.

Figure 4: Computational grid. A) Horizontal view of the elliptical pier No. 1 and, B) Vertical view of the elliptical pier.

Figure 5: Drag coefficients for Pier 1 and 2. Non-stratified water column and uniform current.

Figure 6: Mean drag coefficients as function of current angle of attack for Pier 1. Non-stratified water column and uniform current. Errorbar indicates the standard deviation. Solid line: $\mathrm{CD}, \alpha-\mathrm{CD}, \alpha=0=\mathrm{constant} \cdot \sin 2(\alpha)$; where the constant was found by least squares to be 3.46 .

Figure 7: Density profiles before, during, and after a test $(\mathrm{h}=0.571 \mathrm{~m}, \mathrm{U}=0.21 \mathrm{~m} / \mathrm{s}$ and $\Delta \mathrm{S}=$ 10). Arrows indicate direction of change during the test. The density increased in the top of the water column, decreased in the bottom of the water column and the interface was lowered. 
Figure 8: Illustration of the bulk flux Richardson number for test with $\mathrm{h}=0.571 \mathrm{~m}, \mathrm{U}=0.21 \mathrm{~m} / \mathrm{s}$ and $\Delta S=10$. The potential energy was found by integrating the density profiles in Fig. 7 corrected for difference in average density. Here presented as the change in potential energy relative to the initial density profile. The error bars indicate the variation in the average density of the stratified water column. The work was calculated from the actual measured drag force.

Figure 9: Bulk flux Richardson number as function of the flow velocity. Equations for approximations are given in Table 2 based on the discusions presented later.

Figure 10: Total mixing of an initially two-layered water column.

Figure 11: Schematic illustration of mixing due to turbulence in the upper layer

Figure 12: Entrainment velocity as function of the overall Richardson number. 


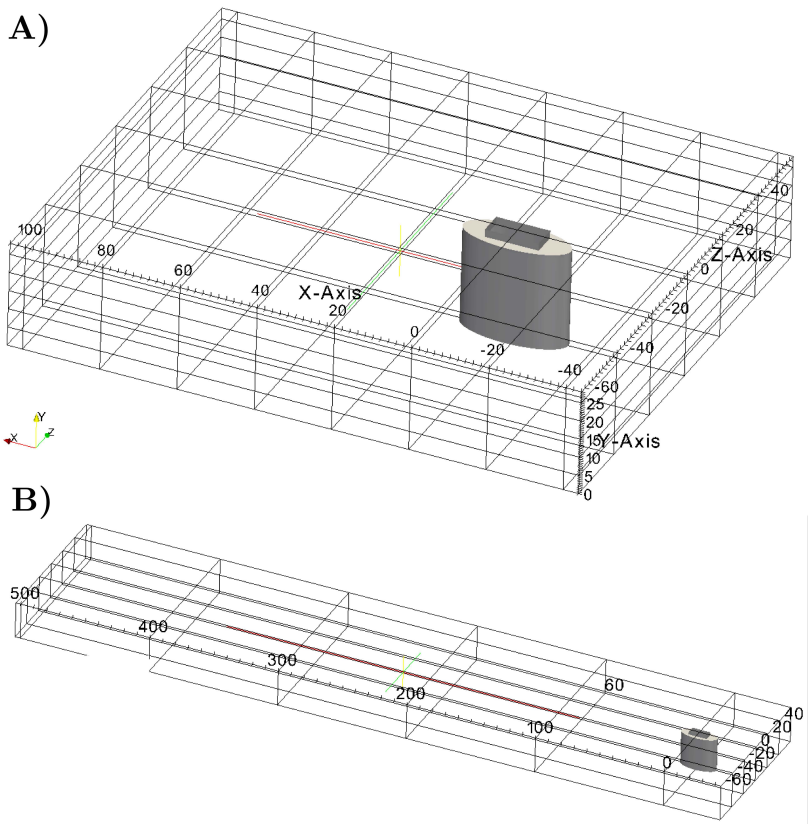
A)

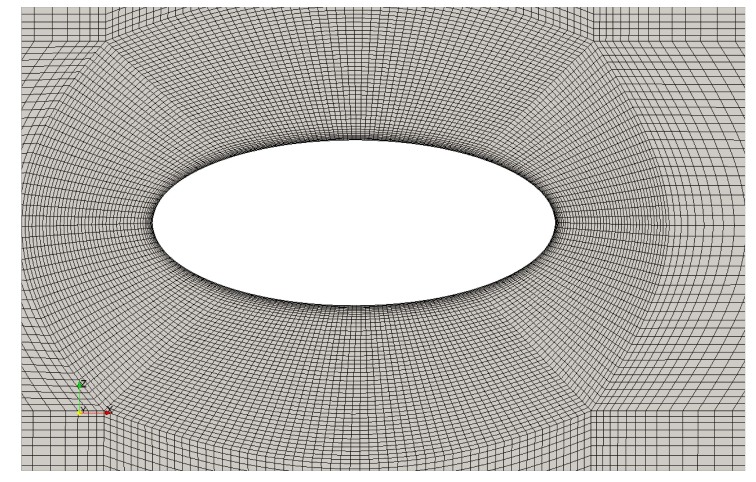

B) 


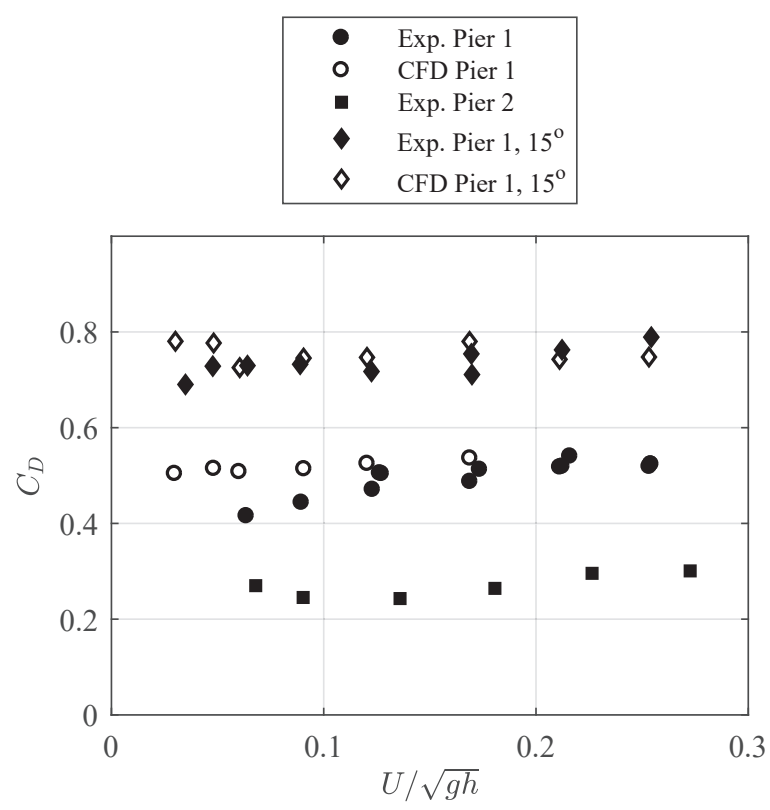




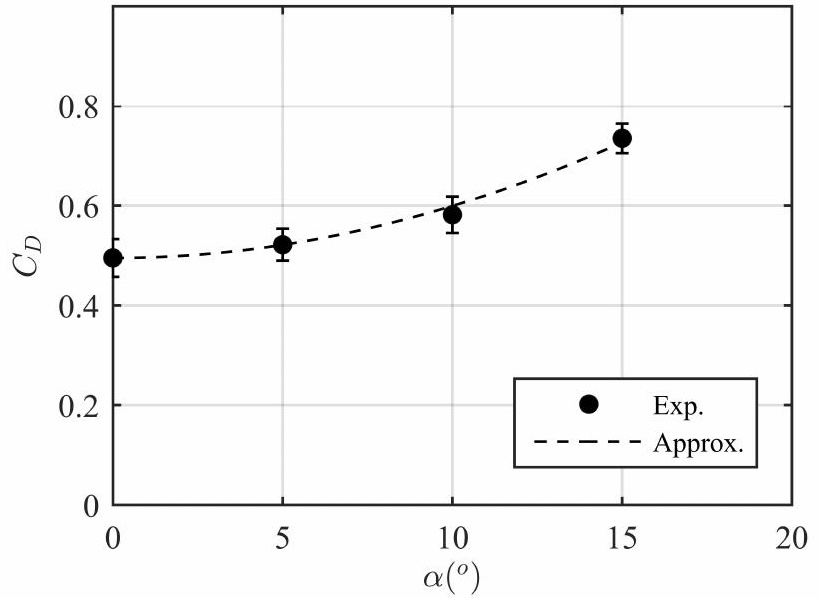




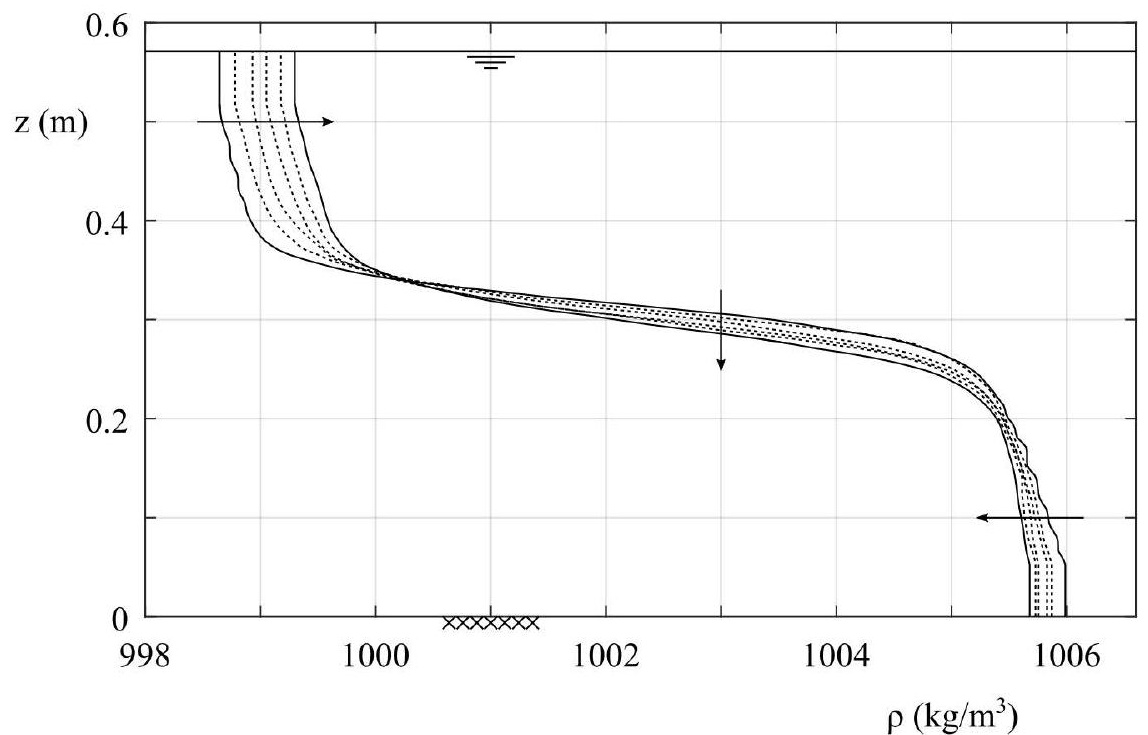




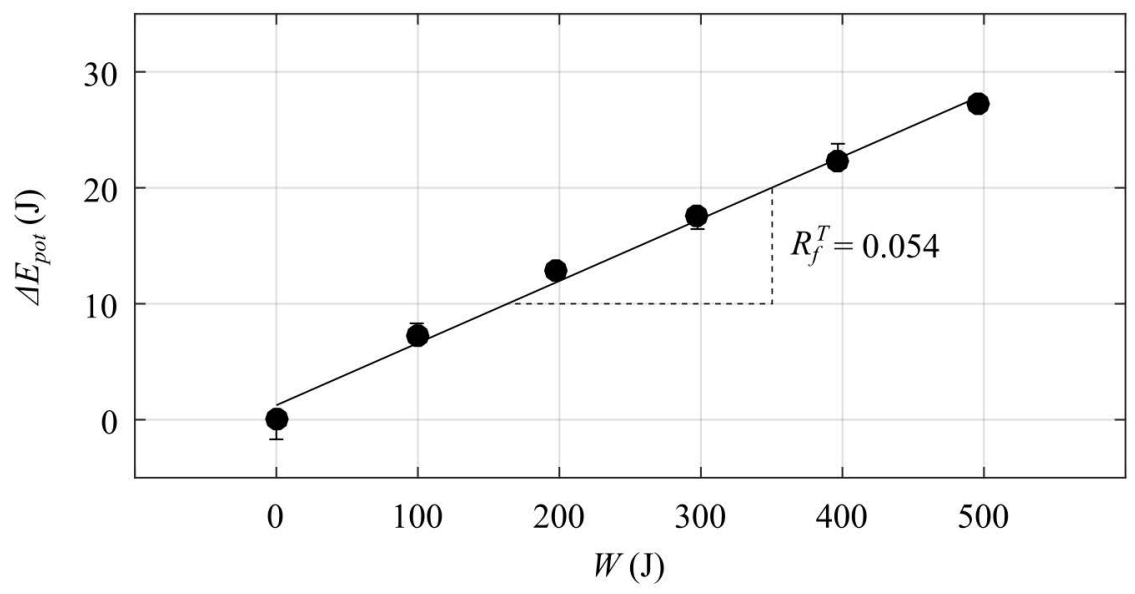




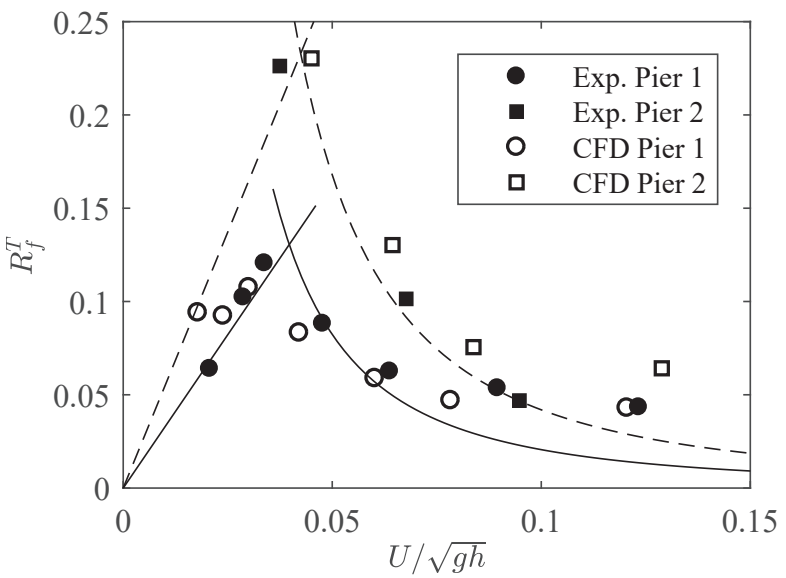




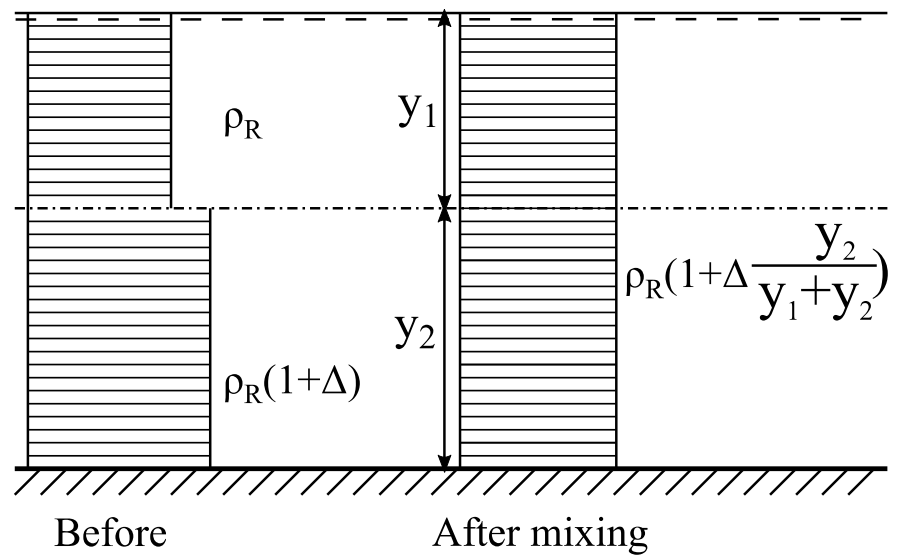




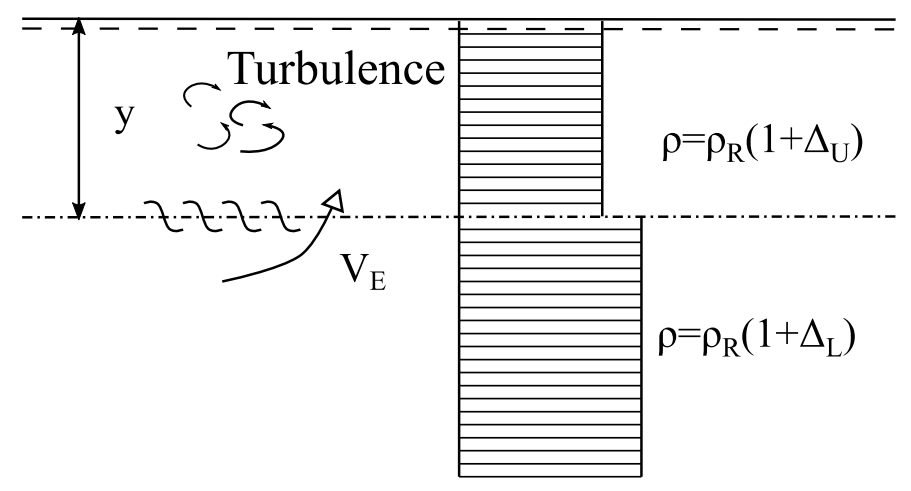




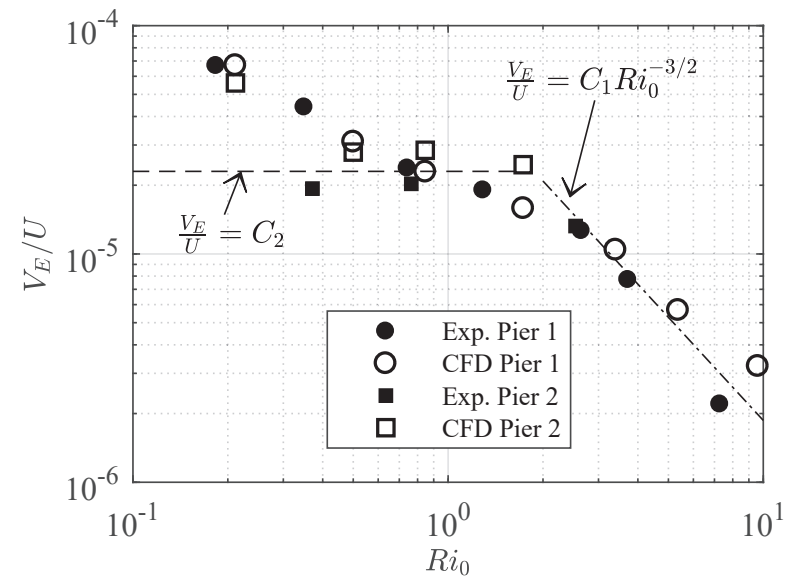

